\title{
Scaffolding and dialogic teaching in mathematics education: introduction and review
}

\author{
Arthur Bakker $^{1}$ (D) Jantien Smit $^{2} \cdot$ Rupert Wegerif $^{3}$
}

Accepted: 24 September 2015/Published online: 14 October 2015

(C) The Author(s) 2015. This article is published with open access at Springerlink.com

\begin{abstract}
This article has two purposes: firstly to introduce this special issue on scaffolding and dialogic teaching in mathematics education and secondly to review the recent literature on these topics as well as the articles in this special issue. First we define and characterise scaffolding and dialogic teaching and provide a brief historical overview of the scaffolding metaphor. Then we present a review study of the recent scaffolding literature in mathematics education (2010-2015) based on 21 publications that fulfilled our criteria and 14 articles in this special issue that have scaffolding as a central focus. This is complemented with a brief review of the recent literature on dialogic teaching. We critically discuss some of the issues emerging from these reviews and provide some recommendations. We argue that scaffolding has the potential to be a useful integrative concept within mathematics education, especially when taking advantage of the insights from the dialogic teaching literature.
\end{abstract}

Arthur Bakker

a.bakker4@uu.nl

1 Utrecht University, Utrecht, The Netherlands

2 Saxion University of Applied Sciences, Enschede, The Netherlands

3 University of Exeter, Exeter, UK

\section{Scaffolding and dialogic teaching}

\subsection{Why combine these topics?}

This special issue of ZDM Mathematics Education is about scaffolding and dialogic teaching in mathematics education. There have been several special issues on scaffolding in education (Azevedo \& Hadwin, 2005; Davis \& Miyake, 2004; Elbers, Rojas-Drummond, \& van de Pol, 2013) and review studies (Belland, 2014; Belland et al., 2015; Lin et al., 2012; Van de Pol et al. 2010) but not specifically in mathematics education. Yet the research on scaffolding in mathematics education is growing rapidly, hence a special issue and a review study on this topic seem timely. Moreover, scaffolding has been argued to be an integrative concept (Estany \& Martínez, 2014), which is desirable given the relatively isolated bodies of literature on related topics such as adaptivity, formative assessment or dialogic teaching.

Along with the power and popularity of the concept of scaffolding it is important to explore also the differences with related concepts. For example, it has often been argued that the notion of scaffolding has become used so broadly that it does not mean more than support (Pea, 2004). The metaphor of scaffolding as providing temporary adaptive support is attractive, but the metaphor itself has also been criticized (for a seminal overview see Stone, 1998a, b). Thus what is important is both empirical work on its effectiveness and theoretical work of what counts as scaffolding and what may be implicit in various accounts of this idea. In order to do this we complement and contrast scaffolding with dialogic teaching.

Why dialogic teaching? One of the key mechanisms of what could make scaffolding productive is dialogue. As Stone (1998a, p. 361) concluded: "If we are to make richer 
use of the metaphor, we must focus clearly on the communicational dynamics at the heart of successful scaffolding of children's learning." Connections between scaffolding and dialogic teaching have been noted by many (Bell \& Pape, 2012; Bliss et al., 1996; González \& DeJarnette, 2015). Both scaffolding and dialogic teaching involve contingently responding to the moves made by a student. Both scaffolding and dialogic teaching have their origin in sociocultural movements in educational psychology that refer back to Vygotsky and sometimes also to his contemporary, Bakhtin. Yet there are interesting differences; for example, dialogic teaching does not require withdrawal of support. We anticipated that conversation between the two perspectives could help to make more explicit what are useful conceptualizations and approaches to scaffolding and dialogic teaching. Hence the focus is on both topics.

\subsection{What is scaffolding?}

Scaffolding can be defined as "the process that enables a child or novice to solve a problem, carry out a task, or achieve a goal which would be beyond his unassisted efforts" (Wood, Bruner, \& Ross, 1976, p. 90). Wood et al. (1976) characterized scaffolding as

an interactive system of exchange in which the tutor operates with an implicit theory of the learner's acts in order to recruit his attention, reduces degrees of freedom in the task to manageable limits, maintains 'direction' in the problem solving, marks critical features, controls frustration and demonstrates solutions when the learner can recognize them. (p. 99)

The study of this process originates in research on how mothers help children learn language and play games such as peekaboo (Bruner, 1975a, b; Bruner \& Sherwood, 1976). The metaphor hints at a temporary construction that is used to erect or support a building. It can be removed once the building is finished. In this reading, what is supported is a student's construction of knowledge or skill. Another way to interpret the metaphor is that the temporary scaffolding structure helps people to do work they would not be able to do without that support structure.

Within educational research, the concept of scaffolding has gained popularity over the past decades. One of its attractions is that the concept hints at what is considered good teaching, namely "the active and sensitive involvement of a teacher in students' learning" (Mercer \& Littleton, 2007, p. 18). Where it initially referred to live interaction between tutor and tutee, the concept has been broadened to include collaborative learning (Rojas-Drummond \& Mercer, 2003), peer scaffolding (Fernández, Wegerif, Mercer, \& RojasDrummond, 2001), and whole-class settings (Cazden, 1979;
Puntambekar \& Hübscher, 2005; Smit, Van Eerde, \& Bakker, 2013). The importance of design has also come into the picture, and supporting artefacts have become conceptualised as scaffolds (Davis \& Miyake, 2004). Although originating in the context of problem solving (e.g., building a pyramid), it took some time for the concept of scaffolding to find its place in mathematics education.

\subsection{What is dialogic teaching?}

The term "dialogic teaching" is particularly associated with Alexander's (2008) focus on talk between teachers and students in the classroom. Alexander grounds his approach to dialogue in Bakhtin often quoting the line "if an answer does not give rise to a new question from itself, it falls out of the dialogue" (Bakhtin, 1986, p. 168). Alexander's point in using this Bakhtinian definition of dialogue is that it is only by engaging in live dialogue, either with each other, directly with the teacher, or vicariously by listening to others in dialogue, that students learn to think. This understanding of dialogue as a form of open ended shared inquiry links Alexander's 'dialogic teaching' to Nystrand's 'dialogic instruction' (Nystrand, 1997), Matusov's 'dialogic pedagogy' (2009), Wells' 'Dialogic inquiry' (Wells 1999a, b), Flecha's 'dialogic learning' (2000) and Wegerif's 'Dialogic education' (2007; 2013). What all of these approaches to teaching have in common is a stress on the importance of teaching for dialogue as well as teaching through dialogue. In other words, the aim of education is not only that the students will learn something that the teacher already knows but also that the students will learn how to ask open questions and how to learn new things for themselves through engaging in dialogic inquiry.

\subsection{Aims of the special issue and this introductory review article}

The aim of this special issue in ZDM Mathematics Education is to bring together current state-of-the-art research on scaffolding and dialogic teaching in mathematics education, so that the mathematics education research community has an up-to-date overview of what is known about scaffolding and dialogic teaching but also of possible caveats and future directions. In this introductory and review article, we

- Describe the historical origin and extensions of the scaffolding idea (Sects. 2.1 and 2.2);

- Summarise definitions and characteristics of the scaffolding concept and metaphor (Sect. 2.3);

- Provide a survey of the recent literature in mathematics education on scaffolding (Sect. 3) and dialogic teaching (Sects. 4, 5); 
- Argue why scaffolding, when enriched with ideas from dialogic teaching, can be an integrative concept (Sect. 6).

\section{Scaffolding}

\subsection{A brief history of scaffolding}

As observed by Renshaw (2013), the metaphor of scaffolding is almost always traced back to Wood et al. (1976). As the quotations below illustrate, the historical origin is more complicated. Already in 1963, Ausubel (1963) used the notion of "ideational scaffolding" with relation to the advance organisers for which he became famous (see Reiser \& Tabak, 2014, p. 44). Ausubel worked in the Piagetian constructivist tradition, which was different from the Vygotskian one in which Bruner can be situated (even though Bruner, 1986, did not agree with everything Vygotsky wrote).

Before 1976, Bruner used the concept of scaffolding in several publications (e.g., Bruner, 1975a, 1975b). He informally used the term "loan of consciousness" for what is going on in scaffolding (Wood, 2003). More formally, Bruner used the term "vicarious form of consciousness and control" (1985, p. 215, cited in Holton \& Clarke, 2006). Most relevant to mathematics education are the reports on problem solving, in particular building a pyramid puzzle. In these studies, the interaction between mother and child was analysed as an interactive system of exchange. Wood and Middleton (1975, p. 19) describe this phenomenon eloquently but without using the term scaffolding.

From these references we can conclude that the idea was "in the air" (Pea, 2004, p. 424). The article by Wood et al. (1976) was certainly neither the first to use the scaffolding metaphor, nor the first to describe the phenomenon that they came to coin with the metaphor. However, it is considered the first in which the metaphor was extensively discussed and underpinned with empirical data (cf. Stone, 1998a, p. 345).

From this brief historical overview, we highlight a few observations. The concept of scaffolding was clearly an analytic one to describe the course of particular interactions (Wood \& Middleton, 1975). What is further noteworthy is that Wood and Middleton focused on a so-called "region of sensitivity to instruction":

Ideally, the child should be asked to add one extra operation or decision to those which he is presently performing. This level of intervention we have termed the 'region of sensitivity to instruction' and our hypothesis is that the most effective instructors will concentrate their instructional activity within this region. (p. 182)
In retrospect, this region seems to be an instructional variant of Vygotsky's zone of proximal development (ZPD), which he defined as the distance between a child's actual developmental level, shown by independent problem solving, and their potential development shown by their ability to solve problems with an adult (Vygotsky, 1978, p 86). This will not be surprising because Bruner was very familiar with Vygotsky's work since the early 1960s (Pea, 2004; Stone, 1998a). It is also interesting to note that they studied mothers and children as systems with a "shared programme of action" (Wood \& Middleton, p. 189). We emphasise this focus on shared action systems because it is neglected in some modern usages of the scaffolding term.

\subsection{Social and technological extensions of the scaffolding concept}

The concept of scaffolding started to travel, as popular concepts typically do (Bal, 2009). The idea of scaffolding was quickly broadened to other modalities, agencies and settings than the tutoring process analysed by Wood et al. (1976). This is fine as long as scholars do not keep rigidly to the original setting or use it sloppily for any kind of support (as stated by Reiser \& Tabak, 2014, p. 56). We therefore discuss how the scaffolding concept was extended (cf. Lajoie, 2005).

Pea (2004) observed that the concept has social and technological dimensions. We first discuss how the scaffolding concept became extended in the social dimension, and then in the technological dimension. With respect to the social dimension, Belland (2014) speaks of three different modalities: one-to-one interaction, peer, and computer/penpaper-based scaffolding. Holton and Clarke (2006) even suggested self-scaffolding (meta-cognition). Mothers and tutors were generalized to teachers or even "more knowledgeable others". The dyadic interaction turned out to be nonessential: also groups of pupils could be scaffolded; and peers could scaffold each other. Somewhat more contentious was the extension to whole-class interaction (Cazden, 1979; Hogan \& Pressley, 1997). Would not that require there to be something like a group ZPD, or responsiveness to groups rather than individuals? This group ZPD effect was studied by Fernandez et al. (2001). Later Smit et al. (2013) argued there is sufficient ground to define and study whole-class scaffolding while doing justice to what characterizes scaffolding (see also Zolkower et al., 2015).

Williams and Baxter (1996) further made a helpful distinction between social and analytic scaffolding (picked up by, e.g., Nathan \& Knuth, 2003; Speer \& Wagner, 2009). Social scaffolding refers to the support of social norms in classroom discussion (cf. Makar et al., 2015), whereas analytic scaffolding focuses on the (mathematical) content. It has been argued that a balance between the two types is crucial (Williams \& Baxter, 1996). 
Apart from the social interaction extension, there is also an extension toward technology or, more generally, artefacts (Quintana et al., 2004; Sherin et al., 2004). More and more scholars started to characterize artefacts, including computer software, as scaffolds (e.g., Guzdial, 1994). It is true that such tools can play an important role in supporting students toward particular goals (Belland et al., 2015). However, as Pea (2004) notes, technological scaffolds, by themselves, are not responsive. Even intelligent tutoring systems cannot be responsive in the sense that humans can be (Brandom, 2000). So rather than focusing on tools scaffolding student learning processes, and in line with the historical origin of the concept (Sect. 2.1), it is crucial to consider the whole system in which these tools function as scaffolds. After all, it is mostly the teacher who decides when to use tools and when to withdraw them from instruction.

The topic of tools as scaffolds raises the question of design. More and more educational scholars became interested in the design of such scaffolds but also of education that aims to enact the idea of scaffolding (see also Tabak, 2004, p. 310).

\subsection{Definitions and characteristics of scaffolding}

Over time many different definitions of scaffolding have been formulated. We have already cited some original sources in Sect. 2.1. An often cited definition of scaffolding by Maybin, Mercer and Stierer (1992, p. 188) is:

It is help which will enable a learner to accomplish a task which they would not have been quite able to manage on their own, and it is help which is intended to bring the learner closer to a state of competence which will enable them eventually to complete such a task on their own.

Gibbons (2002) defined scaffolding as temporary, intentional, responsive support that assists learners to move towards new skills, concepts or levels of understanding. Stone (1998a, p. 352) saw as the key of many discussions on the concept the

joint but necessarily unequal engagement in a valued activity, with a gradual shift in responsibility for the activity. Central to this image are the notions of affective engagement, intersubjectivity or shared understandings, graduated assistance and transfer of responsibility.

Intersubjectivity here has the very specific meaning of partial sharing of perspectives.

Thus, most definitions point to similar characteristics. Which of these should be considered defining characteristics depends on the context in which the concept is used.
For example, reviewing a decade of research on teacherstudent interaction, Van de Pol et al. (2010) considers three characteristics to be central to scaffolding (see Stender \& Kaiser, 2015, for a figure).

1. Contingency: teachers adapt their support to students. Diagnostic strategies are considered a tool for contingency.

2. Fading: gradual withdrawing of support.

3. Transfer of responsibility: by fading, teachers transfer responsibility to students, thus handing over to independence. Of course, this teacher action only works if students take this responsibility. This latter process could be called uptake of responsibility.

In the context of whole-class scaffolding, Smit et al. (2013) argued for emphasising diagnosis and proposed the following defining characteristics: diagnosis, responsiveness and handover to independence (see also Stone, 1998a and Puntambekar \& Hübscher, 2005).

Apart from these defining characteristics, many more features of scaffolding have been noted. For example, in their design-based research, Smit and Van Eerde (2011) noticed that awareness is a crucial condition for diagnosis. Without awareness of the importance of language for mathematical reasoning, in their case, a teacher may not be aware of the linguistic support second-language learners of mathematics need. Furthermore, intention is a crucial link between responsiveness and handover: A responsive action is done with the intention to help students do something more independently or on their own responsibility (see also Maybin, Mercer, \& Stierer, 1992).

As emphasized by many scholars (e.g., Mercer, 2008), learning is a long-term process that requires longitudinal analyses. This longitudinal perspective brings to mind features of scaffolding that Smit et al. (2013) have observed in the analysis of whole-class settings:

a. Layered nature: Diagnosis is not only done in live interaction. A teacher may take home student work and notice that many students have a similar problem that needs attention in the next lesson. This hints at the fact that the long-term scaffolding process may also take place outside live interaction, indicating that there is another layer of scaffolding not explicitly addressed in the original literature on tutoring processes.

b. Distributed: In the long run, diagnoses, responses and attempts to handover to independence are distributed over several sessions, and possibly also outside sessions or lessons. These actions are thus distributed. For example, the diagnosis of what a pupil struggles with may be distributed over teacher, parents and a monitoring computer system, just like the responsive strategy to remediate the problem. 
c. Cumulative: A specific episode of learning to do something is seldom a one-off event. It is the cumulative effect of all diagnoses, responses over time, not only during live interaction but also outside it (e.g., re-design).

The scaffolding metaphor is attractive and has potential for education, but over time several concerns have been expressed (see Stone, 1998a). One concern is that the scaffolding idea is sometimes interpreted or operationalised as one-sided, input-driven or other-driven. Searle (1984) wittily asked about such unjustified usage: Who's building whose building? A next point is the assumption of an idealized relationship between teacher and student. As pointed out by for example Broza and Kolikant (2015), students often resist the kind of interaction or dialogue required for scaffolding. Another concern is that scaffolding research is often task-oriented. A related concern, in line with the aforementioned idea of dialogic teaching, is that the scaffolding metaphor suggests a predefined building (blueprint). Some cultural-historical activity theorists such as Engeström considered it to be "restricted to the acquisition of the given" (as cited by Stone, 1998a, p. 350). Despite such caveats, the construction metaphor of scaffolding became popular, possibly because it appealed to both constructivist and sociocultural theorists alike.

\section{Review of recent scaffolding literature in mathematics education}

\subsection{Approach to the scaffolding review}

We now review the available publications in mathematics education of the past 5 years (2010-2015) as found through ERIC, a database dedicated to educational research. Searching for scaffold* AND mathematic* in title and abstract, we found 243 hits (June 2015). By means of applying the following criteria 21 publications could be included.

- The reported research study is within mathematics education (e.g., excluding studies that focus on science and/or technology)

- Scaffolding is central to the publication (e.g., included in data analysis or theoretical framing)

Next we summarised these 21 articles in terms of the following questions:

1. What is scaffolded?

2. Who or what is doing the scaffolding?

3. How was scaffolding enacted?

4. What were main conclusions or interesting points?
Answers to these questions were summarised in a table along with other information such as grade and domain. Table 1 is the result. The same analysis was then applied to the scaffolding articles in this special issue (Table 2).

\subsection{What is scaffolded?}

As can be seen in Tables 1 and 2, what is scaffolded can be quite diverse. Most studies emphasize what Williams and Baxter (1996) call analytic scaffolding, so content-related understanding. This includes generally formulated content such as problem solving, mathematical thinking, inquiry and modelling, but also more specific learning goals, such as arithmetic, algebra, geometry, probability, statistics, calculus and number theory. Mathematical language also serves as the goal of scaffolding (Cohrssen et al., 2014; Esquinca, 2011; Prediger \& Pöhler, 2015; Smit et al., 2013).

Some studies focus on social scaffolding, the support of norm development required for productive classroom interaction (Makar et al., 2015; Roll et al., 2012). Kazak et al. (2015) combine both analytic and social scaffolding, and make the link between scaffolding and dialogic teaching by highlighting scaffolding dialogic talk for conceptual breakthrough. Another way to combine social and analytic scaffolding is by focusing on promoting participation in mathematical practices (Marshman \& Brown, 2014; Moschkovich, 2015), because the social is an intrinsic part of such practices. Affective scaffolding is rarely studied. One exception is the study by Schukajlow et al. (2012), which found positive effects of an "operative strategic scaffolding strategy on enjoyment, value, interest and self-efficacy." Toh et al. (2014) studied both students' dispositions and mathematical problem solving skills. Watson and de Geest (2012) included confidence in their observations. Affective scaffolding deserves more research because affect is an important part of learning.

Not only students but also teachers can be scaffolded. In the cases of Nason et al. (2012) and Sleep and Boerst (2012) future (pre-service) teachers in primary mathematics education are the ones who are scaffolded. What is scaffolded is their pedagogical content knowledge about geometry (Nason et al.) and their practices of eliciting and interpreting children's arithmetical thinking (Sleep \& Boerst) respectively. We think that research about scaffolding teachers is worth conducting (see also Visnovska \& Cobb, 2015), especially if the aim is to teach them how to scaffold their students (practice what you preach). One skill that many teachers struggle with is design (Nason et al.), hence more research on how to scaffold teachers to redesign their curriculum seems timely. 


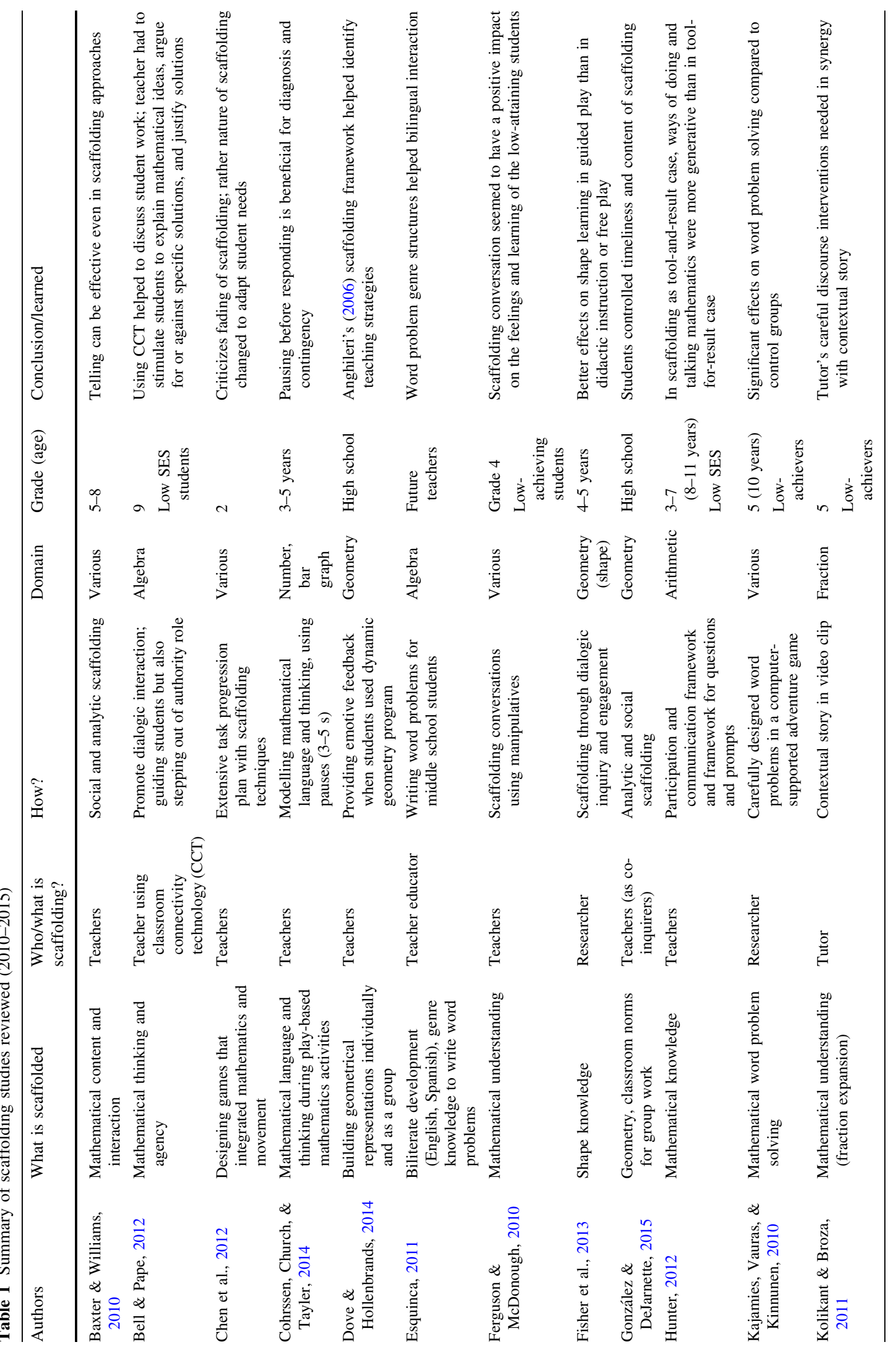




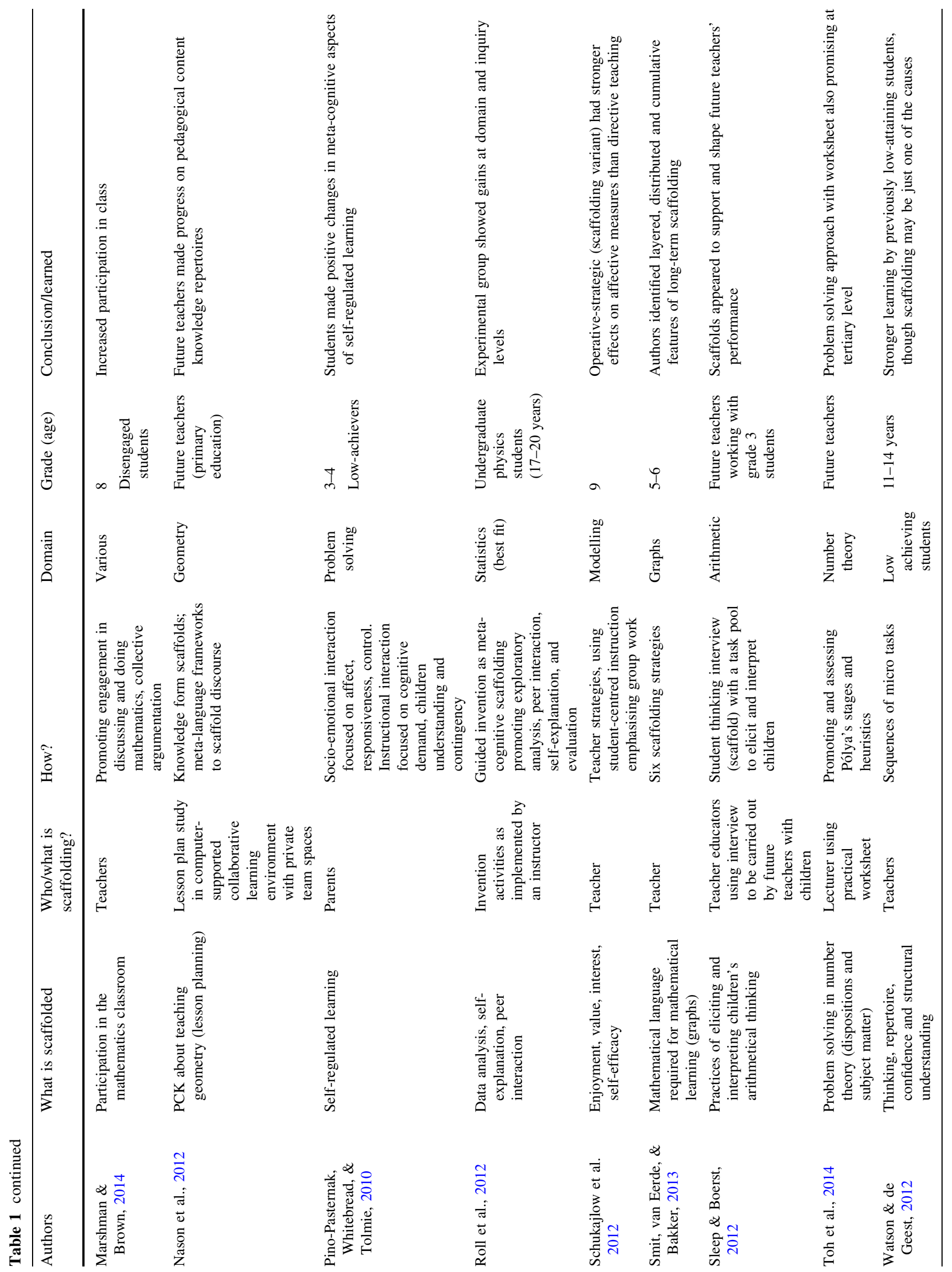




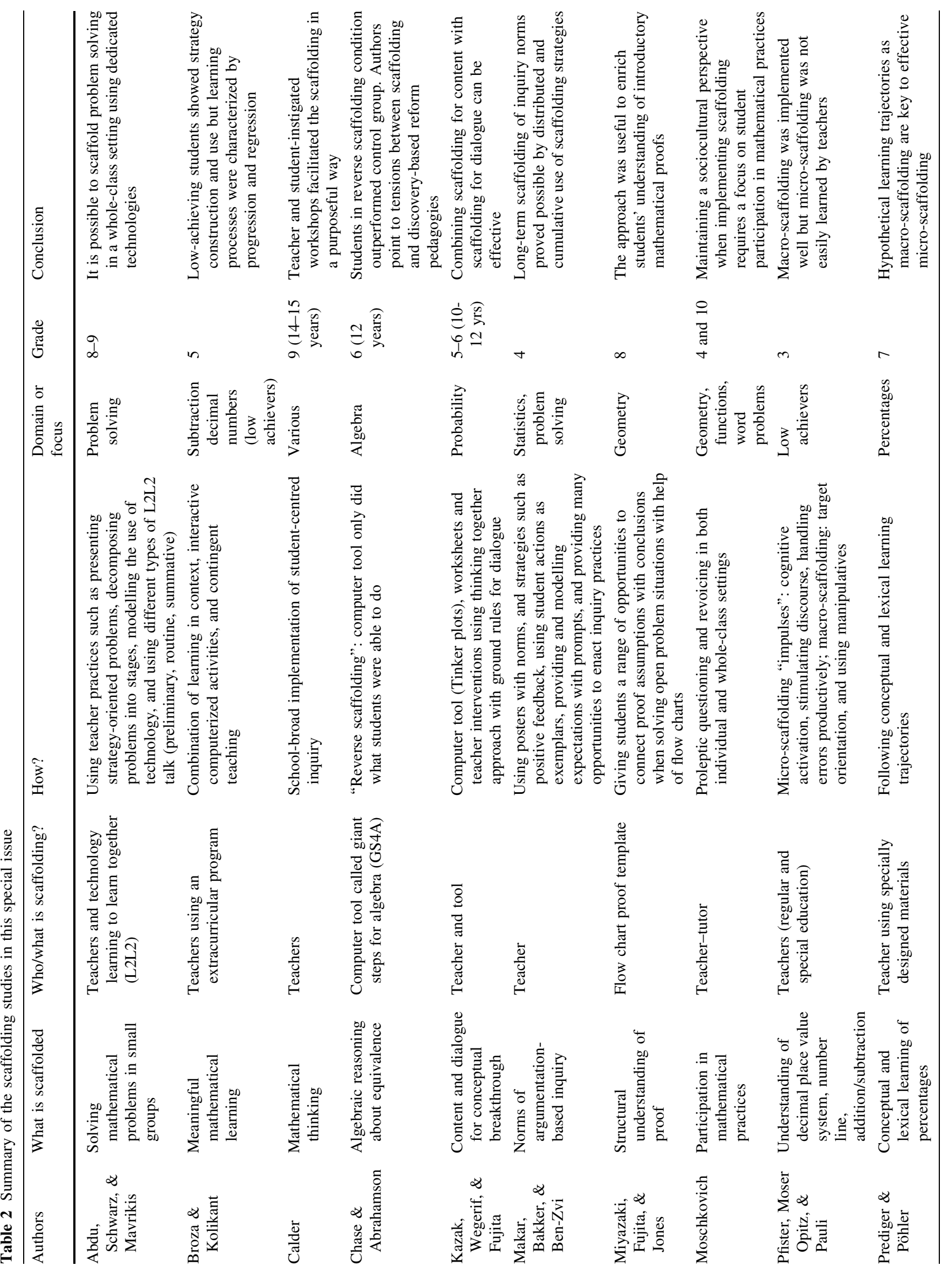




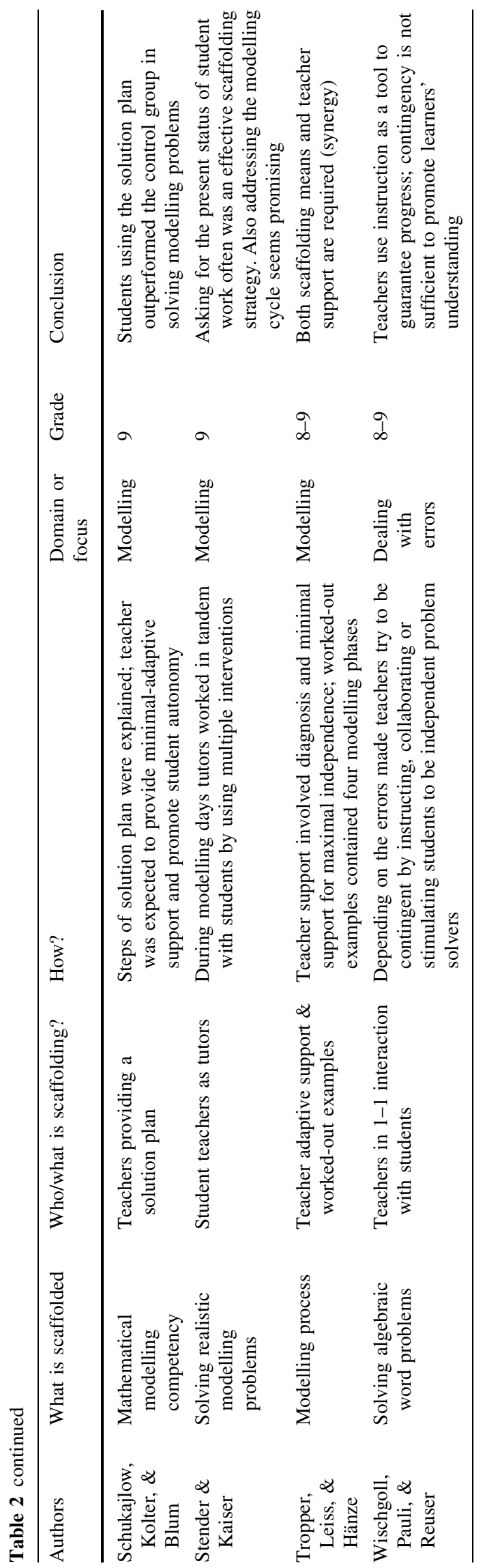

3.3 Who or what is doing the scaffolding?

We prefer to reserve the agency of scaffolding to human beings. Even if tools or artefacts function as scaffolds, it is the judgement of teachers (typically) how to use these in mathematics education. The overviews show that teachers (or their educators) can use many different ways.

Artefacts can play an important role in the whole system of teaching and learning. It is therefore that scaffolds are best considered to be mediators of scaffolding (Davis \& Miyake, 2004) in line with the idea of distributed scaffolding and the synergy between different types of scaffolding (Tabak, 2004; Tropper et al. 2015).

A distinction is made between hard and soft scaffolds (Brush \& Saye, 2002). Hard scaffolds are static ones given beforehand. Among the successful hard scaffolds are solution plans (Schukajlow et al., 2015), proof flow charts (Miyazaki et al., this issue) and worked-out examples (Tropper et al., 2015). Soft scaffolds are dynamic and used on-the-fly. As many articles testify, technology can be sometimes used as soft scaffolds, for example to promote dialogue among students or future teachers (Abdu et al., 2015). But it can also be used for mathematical exploration and feedback (Chase \& Abrahamson, 2015; Dove \& Hollenbrand, 2014; Kazak et al. 2015).

Several authors emphasize that scaffolding is not an input-driven, teacher-centred, one-way process with a quantifiable degree of scaffolding (more or less support). For example, González and DeJarnette (2015) show that students use different ways to slow teachers down who go too fast. Calder (2015) emphasises that also students have their role in the process, in this case in implementing student-centred inquiry.

One issue to highlight is the difference between scaffolding and distributed cognition. As Pea (2004) noted, some tools (e.g., calculators) do not disappear once students have developed particular skills. In such cases it does not make sense to use the scaffolding concept; rather, these tools become part of what is called distributed cognition, referring to how cognition is partly off-loaded to tools or other people (Hutchins, 1995).

\subsection{How does scaffolding take place?}

The articles offer very diverse approaches to scaffolding. Some emphasize dialogue (Abdu et al., this issue; Bell \& Pape, 2012, Kazak et al., 2015; Kolikant \& Broza, 2011), others teacher strategies (Makar et al., 2015; Pfister et al., 2015; Stender \& Kaiser, 2015), teacher practices (Abdu et al., 2015), or the specific nature of computer tools (Chase \& Abrahamson, 2015; Kazak et al., 2015). The key idea behind the aforementioned artefacts (solution plans etc.) is that they provide meta-cognitive guidance to 
students what to do in which order. Some authors draw on a scaffolding model of Anghileri (2006), which summarises different levels of scaffolding strategies (Dove \& Hollenbrand, 2014). One interesting point is that "telling" is not necessarily at odds with the idea of scaffolding as long as it is contingent to the situation (Baxter \& Williams, 2010).

Moschkovich raises the issue of design. This is more extensively discussed by Prediger and Pöhler (2015) and Smit et al. (2013) as part of design-based research (cf. Bakker \& van Eerde, 2015) in order to design long-term learning trajectories and simultaneously investigate how such trajectories support the scaffolding process.

More research on how fading or handover is realized is certainly welcome, because as Belland (2014) observed, very few scholars ever check if support has really faded and how this could be done. The answer of Prediger and Pöhler would be to incorporate it into the design of educational materials (see also Smit, 2013). Several authors helpfully show the design of task progressions (Chen et al., 2012), sequences of microtasks (Watson \& de Geest, 2012), or hypothetical learning trajectories (Smit et al., 2013). An interesting conclusion by Prediger and Pöhler (2015) is that such macro-scaffolding strategies are crucial to successful micro-scaffolding in live interaction in the classroom. Such levels or layers of scaffolding and the interaction between them are worth further investigation. It has been argued that synergy between different ways of scaffolding is required (Tropper et al., 2015), but little is known how this should be done.

\subsection{Conclusions of articles on scaffolding}

A variety of further conclusions can be drawn from the studies. Here we focus on students needing extra support and on effectiveness.

\subsubsection{Students needing extra support}

Several studies focus on students with some disadvantage (e.g., low-achieving, low social-economic status, disengaged) because they need extra support. Broza and Kolikant (2015) point out that the learning processes of these students include many regressions next to their progressions (a phenomenon also observed by Smit, 2013, Chapter 3). This implies that the diagnosis of such students' learning needs to be ongoing. Teacher cannot assume that once they have diagnosed a student as being able to do something independently, they remain in that state. Broza and Kolikant further point to a condition that has not received proper attention in the scaffolding literature: Students may be resistant to support.

Another advice Broza and Kolikant (2015) give is to provide ample opportunities for low-achieving students to think mathematically. Teachers are often inclined to minimize such situations to avoid failure. Thus there is a tension between on the one hand promoting students' selfesteem and on the other hand helping them progress to higher levels. Offering calibrated support is thus very delicate. One interesting strategy is the use of pauses (Cohrssen et al., 2014) of 3-5 s, which help teachers to diagnose and respond better but also gives students time to think. Furthermore, with low-achieving students it may be even more important to engage them (Marshman \& Brown, 2014). Hence, much more attention to social-emotional aspects of learning should be given, not only in teacherstudent but also in parent-child interaction (Ferguson \& McDonough, 2010; Pino-Pasternak et al., 2010; Renshaw, 2013).

\subsubsection{Effectiveness}

The articles reviewed here empirically show that several strategies can be effective across a wide range of age and domains. Several studies report promising qualitative or observational results that provide proof of principle. Only a few have experimental results that show the effectiveness of their approach (e.g., Fisher et al., 2013; Kajamies et al., 2010; Roll et al., 2012; Schukajlow et al., 2012, 2015). In our view it is therefore too early for a systematic quantitative review study such as meta-analysis of the scaffolding research (cf. Belland et al., 2014). We predict it may well take a decade before there are enough experimental studies of sufficient quality to quantify the gains of various scaffolding approaches compared to regular teaching. Moreover, we note that when measures of scaffolding are used in quantitative studies the concept is sometimes operationalised as a one-dimensional issue of degree of support focusing on a question of which degree is best (e.g., Seethaler et al., 2012). This makes it hard to compare experimental scaffolding studies. In the next section we point to further pitfalls of such experimental studies.

\subsection{Recommendations}

\subsubsection{Scaffolding as a descriptive or prescriptive concept}

A source of potential conceptual confusion is the transition of scaffolding as an analytic concept to scaffolding as an interventionist approach that can be evaluated for its effectiveness. Such transitions from descriptive to prescriptive usage of scaffolding have often gone rather unnoticed in the educational research literature (cf. Belland, 2014).

Originally, scaffolding was an analytic concept used to understand the interaction between child and adult (Wood et al., 1976). Different features and functions were 
identified of an interesting phenomenon that naturalistically occurs and that scholars including Bruner and Wood liked to see in education too. Thus it gradually became a prescriptive concept, something that educators tried to realize deliberately in educational settings, which also asks for evaluation of the effectiveness of such approaches.

It is here that we need to be careful. In the original definitions, the concept of scaffolding includes the handover to independence, fading or transfer of responsibility. Without these happening, there would be no ground to characterize the observed phenomenon as scaffolding. However, a pitfall we have noticed is that researchers aim to evaluate the effectiveness of their scaffolding approaches without clearly separating the intervention from the effects. If they only characterize their approach as scaffolding if all main characteristics of the teaching-learning process fulfil the scaffolding criteria, say diagnosis, responsiveness and handover, then the effects are already built into the concept. It would then be tautological to conclude that scaffolding is effective, because handover to independence (hence learning) is already part of the concept. It is therefore crucial in evaluative intervention studies to clearly define what counts as scaffolding and what exactly the scaffolding approach or intervention was. This requires an analytic distinction between the intervention and effects of the approach.

For some authors (cited in Van de Pol et al., 2010), the successfulness of scaffolding is included in the definition, so if a scaffolding approach does not work the resulting teaching-learning process should not be called scaffolding. They may prefer to conceptualize scaffolding as a dynamical system including teacher, students, and artefacts, in which elements have different types of agency. For these authors it may be preferable to analyse how this system as a whole changes due to particular influences such as by researchers bringing in new ideas. We also endorse this view (Smit et al., 2013). The intention to scaffold is in our view not enough to speak of scaffolding, so it should be empirically evaluated if a teaching-learning process fulfils a set of criteria that justify the term scaffolding (e.g., Smit $\&$ van Eerde, 2013). We therefore recommend to clearly defining what counts as scaffolding, and cleanly separate any scaffolding approach from the resulting teachinglearning processes.

\subsubsection{Scaffolding terminology}

Here we provide some recommendations on terminology.

1. Should we write "a scaffold" or "a scaffolding"? Pea (2004) observes that in English both are possible. However, to avoid confusion and stay in line with the literature we advise calling a support structure "a scaffold." Furthermore, what is it that teacher or tutors do when they scaffold or provide scaffolding? Common terms, found in Van de Pol et al. (2010), are scaffolding means, strategies and interventions. In order to build on the existing literature it is wise to use similar terminology for similar objects and phenomena.

2. Clarify which characteristics are considered key to scaffolding. For example, without evidence of diagnosis, responsiveness and handover to independence, we would not consider teacher-guided interaction and support to be scaffolding (Smit \& Van Eerde, 2013). Other authors may prefer the defining characteristics formulated by Van de Pol et al. (2010).

\section{Dialogic teaching in mathematics}

Dialogic education claims that dialogue and contingent responsiveness are not only a means to teach (tool-forresult) but also an end of teaching (tool-and-result). So the aim of dialogic education in mathematics is not only to teach concepts but also to teach mathematical dialogue in which concepts are questioned and developed (see Kazak et al., 2015).

One difference between education for dialogue (dialogic education) and most accounts of education for distributed cognition is that the distributed cognition approach does not usually distinguish between two very different kinds of mediation, mediation by voices and mediation by things including tools, systems and words considered as cognitive tools. However, as Bakhtin points out, relationships between things are very different from dialogues between voices (Bakhtin, 1986, p 138 and 162). Each participant in a dialogue takes the perspective of the other into account when they speak. The boundary between subjects is therefore not a simple demarcation line but it opens up into a shared space of meaning.

The concern about scaffolding implied here is that whereas scaffolding can describe how we teach the ability to use mathematical concepts correctly it does not describe how we might encourage children to think for themselves in an open-ended way such that new things can be learnt that are not known in advance, which means to think 'creatively'. According to Wegerif (2007) the dialogic space that opens between voices in dialogue is the origin of creativity. To learn to be creative is to learn how to 'step back' from fixed identity commitments and 'cognitive schemas' and allow new voices and ways of seeing to emerge. Teaching for creative thinking implies drawing students into genuine open-ended dialogue. This implies a contrast with some versions of scaffolding that link 
scaffolding to acquiring mastery of a cognitive tool, since on this model dialogue is not to be understood as a tool that a self uses but as the stepping back of the self to allow something larger to flow through.

Education into a 'distributed cognition' system that is not understood dialogically is education only for the maintenance of that pre-existing system. This might be useful, but education also has the function of empowering students to question, challenge and transform existing systems. Mathematics education should, on a dialogic vision of education, not only teach students about what has been done in the past, important as this is, but also equip students to be able to think creatively so as to be able, potentially, to take mathematics further in the future.

A short narrative can be given to illustrate the distinctiveness of dialogic education from scaffolding. This is a description of how a father came to understand his child's different way of understanding a mathematics problem from the way in which it was supposed to be understood by the class teacher. It is true story described in Wegerif (2013, pp. 58-62) and summarised briefly here. A boy came home from school and showed his father a mathematics problem that had been marked as wrong. The boy was confused as he thought that his answer was right.

The question was a hexagon with a question mark (Fig. 1). The answer was the angle. The boy had put $90^{\circ}$ and did not know why this was wrong. His father explained that it was a hexagon so each of the triangles was equilateral and all the internal angles of each triangle were $60^{\circ}$ so the answer had to be $60^{\circ}$. He did so in a way that tried to scaffold the information, breaking it down into parts and checking for understanding at each stage but it was clear that the child already knew the argument about hexagons and equilaterals but still remained baffled. It was clear that they did not understand each other. Eventually, after some false starts, the boy made it clear that for him the shape was not a hexagon but a cube (Fig. 2).

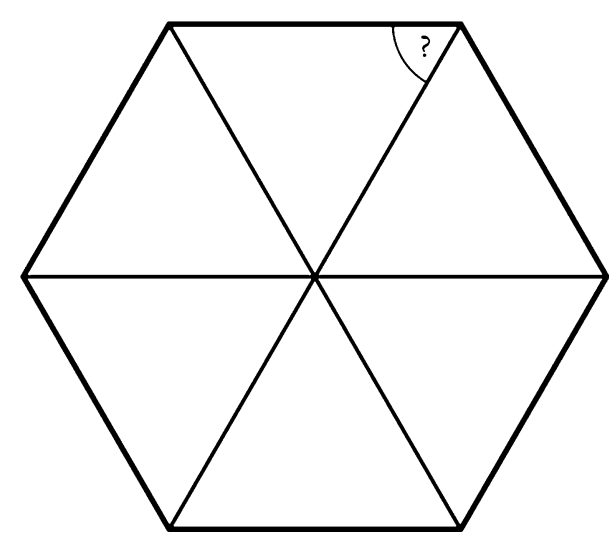

Fig. 1 Hexagon?

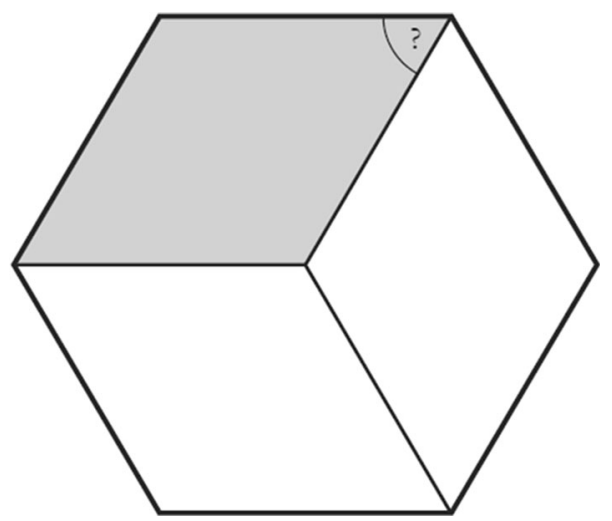

Fig. 2 Cube?

Squinting his eyes and looking again as the child had looked, the father came to see that the image could, in fact, also be seen as a cube. As a cube the boy's answer of $90^{\circ}$ was correct. The father had learnt something.

The general point is that every act of scaffolding into a correct answer always already assumes a cultural and historical context that makes it the correct answer. To teach for creativity we have to teach in a way that allows for it to be seen differently. Here the father was teaching creativity by listening, by pausing, by showing respect and by allowing himself to be led by the child and to learn from the child. Dialogic education is not just oneway but two-way. The aim is not just to reach the correct answer but also to be able to see things from multiple perspectives. Here the child learnt to try to figure out how the teacher was seeing things and what answer he was supposed to give while also maintaining his ability to see things in his own, different way and the father learnt that what he had assumed was a simple problem could be seen in more than one way. Dialogic teaching then is about inducting students into genuinely open-ended learning dialogues through the example of such dialogues. In this case learning how to ask good questions, how to show respect for other views, however wrong they initially appear, and how to be open to taking on new perspectives.

As we already mentioned when we discussed the idea of a region of sensitivity to instruction, scaffolding, as a concept, is closely allied to Vygotsky's concept of a 'Zone of Proximal Development' (ZPD). The idea of the ZPD is of the zone of what the child can do when supported (or even scaffolded) by an adult. Like scaffolding it involves a dialogic element in that, in order to help take children through the zone, the adult has to see things from the child's point of view and be contingently responsive to the child, checking for understanding and adapting explanations. However, as presented by Vygotsky, this zone was seen very much as a one-way or asymmetrical process in 
which the child was brought up to see things as the adult already saw them.

To understand teaching for creativity all we need to do is to expand and radicalize Vygotsky's original insight that there is a kind of dialogic space in education. In the ZPD Vygotsky applied the opening of dialogic space as a limited tool within a larger asymmetrical educational theory as a way of bringing children from participatory thinking (their spontaneous understandings) into systematic thinking (the concepts being taught). Dialogic education agrees that development occurs in the space of possibilities (dialogic space) that opens up in educational relationships, but it claims that this space is not a limited zone that learners pass through; it is also the context of education and the end of education. Widening, deepening and fully inhabiting the space of possibilities that opens up in dialogue is becoming a creative thinker. If we take the space of the ZPD more seriously we can see that this space itself, dialogic space, can be personally appropriated by students, not only the cultural tools and concepts that are negotiated and transmitted within this dialogic space. In teaching a way of thinking, the use of 2D geometrical diagrams or graph paper, or the use of a number system, dialogic education suggests that we do not teach this as simply the 'right way' of thinking but as a perspective which might be useful for some tasks but which is only ever one way of seeing things that usually closes some possibilities at the same time as it opens up other possibilities. In other words we need to teach in a way that keeps alive possibilities for new ways of seeing.

\section{Brief survey of dialogic approaches in mathematics education}

The concept of dialogic teaching is not nearly as popular in mathematics education as the concept of scaffolding. Searches for 'dialogic teaching' and 'mathematics' in both the ERIC database of educational resources and the PsycINFO database limited to abstracts of articles since 2005 produced no returns. However the same search using just the key words 'dialogic' or 'dialogism' and 'mathematics' produces 19 unique returns all of which are concerned with dialogic education in the broad sense. Of these, five are not specifically about dialogic mathematics education being focused on research in the fields of educational technology, philosophy of education and language education. The remaining 14 articles illustrate the range of uses of dialogic in mathematics education.

Wegerif (2007, p. 39) described four different ways in which the term dialogic is used in education:
1. Dialogic as simply 'pertaining to dialogue' with no more technical understanding of dialogic related to Bakhtin required, even when Bakhtin's name is invoked.

2. Dialogic as about the open and responsive nature of texts and utterances applying Bakhtin's literary analysis to classroom discourse and also to the formation of more dialogic selves on the model of Bakhtin's account of the dialogic author, who, like Dostoyevsky, allows the voices of his or her characters to have autonomy.

3. Dialogic as an explicit epistemology of collaborative knowledge construction found in the work of Wells (1999a, b), Mercer (2008) and also Scardamalia and Bereiter (1994).

4. Dialogic as ontology. Most accounts of dialogic are epistemological, seeing dialogue as the means to the end of knowledge construction. Seeing dialogic as ontology suggests that dialogue itself is the end or object or aim of dialogue in education and not merely the means to an end. The educational purpose becomes to improve and expand the dialogue.

Four of the studies found in our brief survey use the term 'dialogic' in the first sense which is its everyday or dictionary meaning of 'pertaining to dialogue' without any further references to a dialogic research tradition. Zazkis and Koichu (2015) offer what they call a dialogic method of presenting research which means presenting research in the form of a dialogue between researchers. Dekker, Elshout-Mohr, and T. Wood (2006) also use the term dialogic in a non-technical way. They mainly refer to the self-regulation literature developing this to consider how children regulate each other's learning in small groups. Miller and Glover (2010) use dialogic interchangeably with 'interactive' to refer to a kind of pedagogy that is needed with Interactive Whiteboards in secondary mathematics. Bennett (2010) uses the term 'dialogic' in a similarly loose way through a reference to a guide to quality in classroom discourse, Piccolo et al. (2008, p. 378), who they cited for their definition of the kind of talk they want to see more of in classrooms:

For the purposes of this study, we defined rich, meaningful discourse as interactive and sustained discourses of a dialogic nature between teachers and students aligned to the content of the lesson that addresses specific student learning issues.

This is fine for practical purposes but does not explore further exactly what lies behind the 'dialogic nature' of some discourse.

Solomon (2012) uses dialogic in the second sense listed above, with detailed references to Bakhtinian theory in order to explore the narratives of two women in mathematics 
focusing on the multi-voiced nature of learning and how different cultural gendered voices enter into self-narratives. While this use of what she refers to as 'dialogism' rather than dialogic theory to explore how learners find their own voice within the field of mathematics is very relevant and important it is not directly connected to the focus on dialogic teaching and scaffolding in this special issue.

Nelson and Slavit (2007) apply the third definition of dialogic above with the phrase 'dialogic inquiry' in their practical survey of professional learning basing themselves on Wells (Wells 1999a, b) and Vygotsky without any mention of Bakhtin. Civil and Bernier (2006), like DíezPalomar and Olivé (2015), refer to rather different tradition of 'dialogic learning' associated with Flecha (2000) who bases his dialogic theory more on Freire and Habermas. The sociological background of Flecha can be seen in their study of ways of integrating parents into mathematical communities of learning. Perhaps the link to issues of social justice justifies describing this as a new and distinct use of the term dialogic but, through its reliance on Habermas's theory of communicative action, this usage also fits well with the epistemological dialogic tradition of Wells and Mercer.

The remaining studies found in this brief survey also broadly fit with this epistemologic understanding of dialogic because they consist of detailed analyses of classroom talk focusing on how some uses of language by teachers are more able to open up possibilities, while other uses close down possibilities. Mesa and Chang (2010) look at how teachers engage children in dialogic interaction or manage to close off this possibility through different ways of talking in the classroom. Wagner and Herbel-Eisenmann (2008) explore how the word 'just' has both what they call 'monoglossic' (closing down) uses and what they call 'heteroglossic' (opening up) uses. Truxaw DeFranco (2007a, b, 2008) and Truxaw Gorgievski and DeFranco (2008) perform similar detailed analyses using a coding scheme which explores the patterns of meaning making in maths discourse with a focus on the balance between 'univocal' (closing down) and 'dialogic' (opening up) utterances over time and how this leads or fails to lead to new insights and understanding. Rickard (2014) refers to Truxaw and DeFranco's work in his similar study focusing on the development of understanding of the idea of a perimeter.

These and other studies not picked up by this simple literature search method, indicate that the idea of dialogic is entering into mathematics education research in ways that are often related to studies of scaffolding through talk and tools in classrooms but that do not all draw upon the same sources and that often assume a fairly simplistic understanding of dialogic. The simple or everyday definition of dialogic is not 'wrong' as such but misses an opportunity to use dialogic as a technical term in the way intended by Bakhtin to point to a new kind of educational purpose.
Wegerif's final definition of dialogic, as ontological and not merely epistemological, does not appear directly in our survey but it is worth mentioning as it can be found in at least two of the articles in this volume, Kazak et al. and also the article by Langer-Osuna and Avalos. For Wegerif, it is only this ontological understanding of dialogic that requires the use of dialogic as a distinctive technical term. Most uses of dialogic could be re-written in terms of simple dialogue or 'collaborative learning'. The ontological understanding of dialogic is saying something rather more challenging which is that the 'dialogic space' that can open up in classrooms is the real thing that we should be aiming at and is not merely a means to the end of constructing more tangible things like knowledge.

Only one article focuses solely on dialogic discourse without mentioning scaffolding at all (Otten et al., 2015). This article continues in the tradition of mapping classroom dialogue in terms of dialogic and univocal utterances referring to the work of Truxaw and DeFranco reviewed above. As the authors point out, this work is useful to understand the balance needed between univocal and dialogic utterances in order to co-construct meaning in specific contexts, in this case the context of attending to mathematical precision. Several other articles illustrate the close connection that is often found between ideas of scaffolding and ideas of dialogic in studies of discourse in the mathematics classroom.

The article by Kazak et al. (2015) makes the argument, similar to that originally made by Williams and Baxter (1996) that dialogic teaching does not have to be conceptualised as an alternative to scaffolding but that the two very different concepts can work well together. Specifically they argue that scaffolding by technology and by the teacher can support the creation of a dialogic space in which learning occurs through dialogic processes. In this case the scaffolding includes the use of language prompts, such as cards asking 'why?' which were removed as the group became more competent at dialogic talk.

The same argument is made in the article by Abdu et al. (2015). In this study the focus is on the impact of technological and teacher scaffolding for Learning to Learn Together in mathematics. Learning to Learn Together (L2L2) is a version of the 'Thinking Together' educational approach developed by Dawes, Mercer and Wegerif (2004) precisely to create the conditions of dialogic learning. Although the article by Calder (2015) focusses on scaffolding he also refers to the way in which the teacher can scaffold for 'dialogic relations' which enable the children in the study to generate their own creative new insights.

In a similar way to Kazak et al. (2015) and to Abdu et al. (2015), the article by Díez-Palomar and Olivé (2015) focuses on dialogic learning in Interactive Groups while also discussing the role of the teacher in scaffolding 
interactions to promote dialogic learning. Díez-Palomar and Olivé sum up the complex relationship between teacher scaffolding for dialogue and 'stepping back' allowing the freedom for dialogic learning, writing that: 'the key seems to be somewhere in the middle: taking care of the children, supporting them, warning them when they go off topic, simultaneously with providing them enough freedom to discover the answers by themselves.' This article is interesting in referring to the dialogic learning tradition of the sociologist Flecha (2000) who is more influenced by Freire and Habermas than by Bakhtin. Despite this different lineage the classroom outcome seems similar to the small group learning referred to by Kazak et al. and by Abdu et al.

Zolkower et al. (2015) present a functional-grammatical analysis of a whole-class dialogue. They explicitly address the question of a collective zone of proximal development, as indicated by the use of "I" and "we." The analysis shows how the teacher shaped multiple aspects of doing mathematics by means of careful dialogic moves (cf. González \& DeJarnette, 2015). This article is particularly interesting in showing how visible/external learning dialogues in the classroom interface with and can help to lead to invisible/internal learning dialogues with the 'Generalised Other' of mathematics.

The tension between understanding dialogic teaching as a kind of scaffolding towards an end of knowledge construction and understanding dialogic as a unique end in itself runs through all these articles. This tension is perhaps most clearly brought out in the article by Langer-Osuna and Avalos (2015) which makes a clear contrast, with illustrations from discourse in the classroom, between dialectic reasoning closing in on the right answer and dialogic reasoning where spaces of creative possibility are opened up and valued. This dialectic tradition of reasoning, where the answer is known in advance and the student is guided towards it, fits well with the scaffolding tradition derived from Vygotsky whereas the more genuinely openended dialogic reasoning fits better with Bakhtin's very different ontological commitments. All these studies show that both dialectic and dialogic have their place and can be usefully combined in the mathematics classroom. They also show why it is useful to understand the different causal processes at work behind the emergence of understanding in mathematics and how these different processes can be supported or hindered by teachers.

\section{Scaffolding as an integrative concept}

In the first section we have hinted at the idea of scaffolding having the potential to be an integrative concept in mathematics education. Here we aim to sketch a direction in which this could be done.
In research, it is often necessary to develop more and more refined concepts for increasingly specific purposes. One could think of distinctions between various types of assessment such as diagnostic, formative and summative assessment; and as part of formative assessment for example teacher judgement accuracy (e.g., Krolak-Schwerdt, Glock, \& Böhmer, 2014). Such narrower and more specific foci are important to make progress in research. However, teachers and researchers searching for pedagogical approaches that work in such a complex setting as the mathematics classroom also need concepts that help to structure teaching and learning in a coherent way and orient teachers on the bigger picture. Learning theory should offer such a coherent big-picture understanding (Shepard, 2005).

In our experience, scaffolding can provide such structure to teachers; they often find it an appealing image that they find worth pursuing. Like a story or a teaching unit, scaffolding has a beginning, a development and an end. Diagnosis comes first: what do students actually know? Where are the problems? Then, in a scaffolding approach, teaching is responsive to whatever is diagnosed on the fly or in student work. At the end of a unit, students have ideally achieved particular learning goals.

In each of these three phases different specialised and often isolated bodies of literature are at stake. For example, in the diagnosis phase we have already pointed to various forms of assessment that can be helpful to diagnose students' actual levels of development, and thus their zone of proximal development. Teacher awareness (Mason, 1998; Smit \& Van Eerde, 2011) and teacher judgement accuracy (e.g., Krolak-Schwerdt et al., 2014) seem to be crucial as the basis for adaptive, contingent or responsive teacher action. More research on these topics is certainly welcome, because adaptivity requires accurate judgement.

In the development phase resources for responding adaptively are endless. Here we only discuss the family resemblances between scaffolding and some other approaches such as adaptivity and formative assessment. As Stender and Kaiser (2015) note, scaffolding and adaptivity share several features, but scaffolding scholars seem to emphasize more the long-term process of reaching the final goal of independence. Scaffolding and formative assessment may both involve assessing prior knowledge and giving feedback, but there is a distinction between "means of assessing" and "means of assisting" (Tharp \& Gallimore, 1991)-that is between questioning that assesses and questioning that assists.

The difference between scaffolding and dialogic teaching is most prominent in the end phase. Much of the scaffolding literature focuses on tasks that can in the end be performed independently. Scaffolding experts, however, could argue that the restriction to tasks or pre- 
defined learning goals is not central to the scaffolding concept. Another way to avoid straw man discussion between scaffolding and dialogic teaching scholars is to make explicit that scaffolding is not only "tool-for-result" but also "tool-and-result" (Askew, 2007; Hunter, 2012). Adaptive support is often ongoing, without a clear endpoint or true autonomy. In such cases, teacher support just changes its nature depending on where students are (Chen et al., 2012; Fernandez et al., 2001; Smit \& van Eerde, 2013). When emphasising dialogic discourse, scaffolding and dialogic teaching can be close allies. Where scaffolding scholars emphasise reducing the degrees of freedom, dialogic teaching scholars stress the opening of a space of possibilities. In our view, both need to happen, just like breathing in and breathing out. In this respect, scaffolding and dialogic teaching processes could be complementary.

We hope that scholars who now concentrate on relatively isolated bodies of literature on the aforementioned or similar topics will collectively take the effort to engage in conversation. We expect that such endeavour, along the lines of networking theories (Bikner-Ahsbahs \& Prediger, 2014), will prove productive for gaining precise understanding of the narrow foci as well as gaining a better understanding of the overall picture. We think that scaffolding, when enriched with ideas from dialogic teaching, would be a suitable candidate in providing such a picture to both researchers and teachers.

Acknowledgments We thank the following colleagues for their helpful comments on earlier versions of this article: Dor Abrahamson, Katie Makar, Nathalie Kuijpers, Dolly van Eerde and Janneke van de Pol.

Open Access This article is distributed under the terms of the Creative Commons Attribution 4.0 International License (http://crea tivecommons.org/licenses/by/4.0/), which permits unrestricted use, distribution, and reproduction in any medium, provided you give appropriate credit to the original author(s) and the source, provide a link to the Creative Commons license, and indicate if changes were made.

\section{References}

Abdu, R., Schwarz, B., Mavrikis, M. (2015), Whole-class scaffolding for learning to solve mathematics problems together in a computer-supported environment. ZDM Mathematics Education, 47(7). doi:10.1007/s11858-015-0719-y

Alexander, R. J. (2008). Towards dialogic teaching: rethinking classroom talk (4th edn). Dialogos. http://www.robinalexander. org.uk/docs/TDTform.pdf.

Anghileri, J. (2006). Scaffolding practices that enhance mathematics learning. Journal of Mathematics Teacher Education, 9, 33-52.

Askew, M. (2007). Scaffolding revisited: From tool for result to tooland-result. In Proceedings of the 31st Conference of the International Group for the Psychology of Mathematics Education (Vol. 2, pp. 33-40).
Ausubel, D. P. (1963). The psychology of meaningful verbal learning: An introduction to school learning. New York: Grune and Stratton.

Azevedo, R., \& Hadwin, A. F. (2005). Scaffolding self-regulated learning and metacognition-Implications for the design of computer-based scaffolds. Instructional Science, 33, 367-379.

Bakhtin, M. M. (1986). Speech genres and other late essays. (trans: McGee, V. W.). Austin: University of Texas Press.

Bakker, A., \& Van Eerde, D. (2015). An introduction to design-based research with an example from statistics education. In A. BiknerAhsbahs, C. Knipping, \& N. C. Presmeg (Eds.), Approaches to qualitative research in mathematics education (pp. 429-466). Dordrecht: Springer.

Bal, M. (2009). Working with concepts. European Journal of English Studies, 13(1), 13-23.

Baxter, J. A., \& Williams, S. (2010). Social and analytic scaffolding in middle school mathematics: Managing the dilemma of telling. Journal of Mathematics Teacher Education, 13(1), 7-26.

Bell, C. V., \& Pape, S. J. (2012). Scaffolding students' opportunities to learn mathematics through social interactions. Mathematics Education Research Journal, 24(4), 423-445.

Belland, B. R. (2014). Scaffolding: Definition, current debates, and future directions. In J. M. Spector, et al. (Eds.), Handbook of research on educational communications and technology. New York: Springer.

Belland, B. R., Walker, A. E., Olsen, M. W., \& Leary, H. (2015). A pilot meta-analysis of computer-based scaffolding in STEM education. Educational Technology \& Society, 18(1), 183-197.

Bennett, C. A. (2010). It's hard getting kids to talk about math: Helping new teachers improve mathematical discourse. Action in Teacher Education, 32(3), 79-89. (Berlin: Springer).

Bikner-Ahsbahs, A., \& Prediger, S. (eds) (2014). Networking of theories as a research practice in mathematics education. Advances in Mathematical Equation. Springer. doi:10.1007/ 978-3-319-05389-9.

Bliss, J., Askew, M., \& Macrae, S. (1996). Effective teaching and learning: Scaffolding revisited. Oxford Review of Education, 22(1), 37-61.

Brandom, R. (2000). Articulating reasons: An introduction to inferentialism. Cambridge: Harvard University Press.

Broza, O., \& Ben-David Kolikant, Y. (2015). Contingent teaching to low-achieving students in mathematics: Challenges and potential for scaffolding meaningful learning. ZDM Mathematics Education, 47(7). doi:10.1007/s11858-015-0724-1

Bruner, J. S. (1975a). A communication to language-A psychological perspective. Cognition, 3(3), 255-287.

Bruner, J. S. (1975b). The ontogenesis of speech acts. Journal of Child Language, 2(1), 1-19.

Bruner, J. S. (1985). Vygotsky: a historical and conceptual perspective. In J. V. Wertsch (Ed.), Culture, communication and cognition: Vygotskian perspectives (pp. 21-34). Cambridge: Cambridge University Press.

Bruner, J. S. (1986). The inspiration of Vygotsky. Harvard: Harvard University Press.

Bruner, J. S., \& Sherwood, V. (1976). Peekaboo and the learning of rule structures. In J. S. Bruner, A. Jolly, \& K. Sylva (Eds.), Play: Its role in development and evolution (pp. 277-285). New York: Basic Books.

Brush \& Saye. (2002). http://www.ncolr.org/jiol/issues/pdf/1.2.3.pdf.

Calder, N. S. (2015). Student wonderings: Scaffolding student understanding within student-centred inquiry learning. ZDM Mathematics Education, 47(7). doi:10.1007/s11858-0150734-z

Cazden, C. B. (1979). Peekaboo as an instructional model: Discourse development at home and at school. Stanford: Department of Linguistics, Stanford University. 
Chase, K., \& Abrahamson, D. (2015). Reverse-scaffolding algebra: Empirical evaluation of design architecture. ZDM Mathematics Education, 47(7). doi:10.1007/s11858-015-0710-7

Chen, W., Rovegno, I., Cone, S. L., \& Cone, T. P. (2012). An accomplished teacher's use of scaffolding during a second-grade unit on designing games. Research Quarterly for Exercise and Sport, 83(2), 221-234.

Civil, M., \& Bernier, E. (2006). Exploring images of parental participation in mathematics education: Challenges and possibilities. Mathematical Thinking \& Learning: An International Journal, 8(3), 309-330.

Cohrssen, C., Church, A., \& Tayler, C. (2014). Purposeful pauses: Teacher talk during early childhood mathematics activities. International Journal of Early Years Education, 22(2), 169-183.

Davis, E. A., \& Miyake, N. (2004). Explorations of scaffolding in complex classroom systems. The Journal of the Learning Sciences, 13(3), 265-272.

Dawes, L., Mercer, N., and Wegerif, R. (2004, second edition) Thinking Together: a programme of activities for developing speaking, listening and thinking skills. Birmingham: Imaginative Minds Ltd.

Dekker, R., Elshout-Mohr, M., \& Wood, T. (2006). How children regulate their own collaborative learning. Educational Studies in Mathematics, 62(1), 57-79.

Díez-Palomar, J., \& Cabré Olivé, J. (2015). Using dialogic talk to teach mathematics: The case of interactive groups. ZDM Mathematics Education, 47(7). doi:10.1007/s11858-015-0728-x

Dove, A., \& Hollenbrands, K. (2014). Teachers' scaffolding of students' learning of geometry while using a dynamic geometry program. International Journal of Mathematical Education in Science and Technology, 45(5), 668-681.

Elbers, E., Rojas-Drummond, S., \& Van de Pol, J. (2013). Conceptualising and grounding scaffolding in complex educational contexts. Learning, Culture and Social Interaction, 2(1), 1-60.

Esquinca, A. (2011). Bilingual college writers' collaborative writing of word problems. Linguistics and Education, 22(2), 150-167.

Estany, A., \& Martínez, S. (2014). "Scaffolding" and "affordance" as integrative concepts in the cognitive sciences. Philosophical Psychology, 27(1), 98-111.

Fernández, M., Wegerif, R., Mercer, N., \& Rojas-Drummond, S. (2001). Re-conceptualizing "scaffolding" and the zone of proximal development in the context of symmetrical collaborative learning. The Journal of Classroom Interaction, 40-54.

Ferguson, S., \& McDonough, A. (2010). The impact of two teachers' use of specific scaffolding practices on low-attaining upper primary students. Mathematics Education Research Group of Australasia.

Fisher, K. R., Hirsh-Pasek, K., Newcombe, N., \& Golinkoff, R. M. (2013). Taking shape: Supporting preschoolers' acquisition of geometric knowledge through guided play. Child Development, 84(6), 1872-1878.

Flecha, R. (2000). Sharing words: Theory and practice of dialogic learning. Lanham: Rowman \& Littlefield.

Gibbons, P. (2002). Scaffolding language, scaffolding learning: Teaching second language learners in the mainstream classroom. Portsmouth, NH: Heinemann.

González, G., \& DeJarnette, A. F. (2015). Teachers' and students' negotiation moves when teachers scaffold group work. Cognition and Instruction, 33(1), 1-45.

Guzdial, M. (1994). Software-realized scaffolding to facilitate programming for science learning. Interactive Learning Environments, 4, 1-44.

Hogan, K., \& Pressley, M. (1997). (Eds.). Scaffolding student learning. Instructional approaches and issues. Cambridge: Brookline Books.
Holton, D., \& Clarke, D. (2006). Scaffolding and metacognition. International Journal of Mathematical Education in Science and Technology, 37(2), 127-143.

Hunter, R. (2012). Coming to 'know'mathematics through being scaffolded to 'talk and do'mathematics. International Journal for Mathematics Teaching and Learning, 13.

Hutchins, E. (1995). Cognition in the wild. Cambridge: MIT.

Kajamies, A., Vauras, M., \& Kinnunen, R. (2010). Instructing lowachievers in mathematical word problem solving. Scandinavian Journal of Educational Research, 54(4), 335-355.

Kazak, S., Wegerif, R., \& Fujita, T. (2015). Combining scaffolding for content and scaffolding for dialogue to support conceptual breakthroughs in understanding probability. ZDM Mathematics Education, 47(7). doi:10.1007/s11858-015-0720-5

Kolikant, Y. B. D., \& Broza, O. (2011). The effect of using a video clip presenting a contextual story on low-achieving students' mathematical discourse. Educational Studies in Mathematics, 76(1), 23-47.

Krolak-Schwerdt, S., Glock, S., \& Böhmer, M. (Eds.). (2014). Teachers' professional development: Assessment, training, and learning. Rotterdam: Sense Publishers.

Lajoie, S. P. (2005). Extending the scaffolding metaphor. Instructional Science, 33(5-6), 541-557.

Langer-Osuna, J.M., \& Avalos, M. A. (2015). I'm trying to figure this out. Why don't you come up here?: Heterogeneous talk and dialogic space in a mathematics discussion. ZDM Mathematics Education, 47(7). doi:10.1007/s11858-015-0735-y

Lin, T. C., Hsu, Y. S., Lin, S. S., Changlai, M. L., Yang, K. Y., \& Lai, T. L. (2012). A review of empirical evidence on scaffolding for science education. International Journal of Science and Mathematics Education, 10(2), 437-455.

Makar, K., Bakker, A., \& Ben-Zvi, D. (2015). Scaffolding norms of argumentation-based inquiry in a primary mathematics classroom. ZDM Mathematics Education, 47(7). doi:10.1007/s11858015-0732-1

Marshman, M., \& Brown, R. (2014). Coming to know and do mathematics with disengaged students. Mathematics Teacher Education \& Development, 16(2), 71-88.

Mason, J. (1998). Enabling teachers to be real teachers: necessary levels of awareness and structure of attention. Journal of Mathematics Teacher Education, 1, 243-267.

Maybin, J., Mercer, N., \& Stierer, B. (1992). Scaffolding in the classroom. Thinking Voices: The Work of the National Oracy Project, 165-195.

Matusov, E. (2009). Journey into dialogic pedagogy. Hauppauge: Nova Publishers.

Mercer, N. (2008). The seeds of time: Why classroom dialogue needs a temporal analysis. Journal of the Learning Sciences, 17(1), 33-59.

Mercer, N., \& Littleton, K. (2007). Dialogue and the development of children's thinking: A sociocultural approach. London: Routledge.

Mesa, V., \& Chang, P. (2010). The language of engagement in two highly interactive undergraduate mathematics classrooms. Linguistics and Education: An International Research Journal, 21(2), 83-100.

Miller, D., \& Glover, D. (2010). Presentation or mediation: Is there a need for "interactive whiteboard technology proficient" teachers in secondary mathematics? Technology, Pedagogy and Education, 19(2), 253-259.

Moschkovich, J. N. (2015). Scaffolding student participation in mathematical practices. ZDM Mathematics Education, 47(7). doi:10.1007/s11858-015-0730-3

Nason, R., Chalmers, C., \& Yeh, A. (2012). Facilitating growth in prospective teachers' knowledge: teaching geometry in primary schools. Journal of Mathematics Teacher Education, 15(3), 227-249. 
Nathan, M. J., \& Knuth, E. J. (2003). A study of whole classroom mathematical discourse and teacher change. Cognition and Instruction, 21(2), 175-207.

Nelson, T. H., \& Slavit, D. (2007). Collaborative inquiry among science and mathematics teachers in the USA: Professional learning experiences through crossgrade. Crossdiscipline dialogue. Journal of Inservice Education, 33(1), 23-39.

Nystrand, M. (1997). Dialogic instruction: When recitation becomes conversation. In M. Nystrand (Ed.), Opening dialogue: understanding the dynamics of language and learning in the english classroom. Language and literacy series. New York: Teachers College Press.

Otten, S., Engledowl, C., \& Spain, V. (2015). Univocal and dialogic discourse in secondary mathematics classrooms: The case of attending to precision. ZDM Mathematics Education, 47(7). doi:10.1007/s11858-015-0725-0

Pea, R. D. (2004). The social and technological dimensions of scaffolding and related theoretical concepts for learning, education, and human activity. Journal of the Learning Sciences, 13(3), 423-451.

Pfister, M., Moser Opitz, E., \& Pauli, C. (2015). Scaffolding for mathematics teaching in inclusive primary classrooms: A video study. ZDM Mathematics Education, 47(7). doi:10.1007/s11858015-0713-4

Piccolo, D. L., Harbaugh, A. P., Carter, T. A., Capraro, M. M., \& Capraro, R. M. (2008). Quality of instruction: Examining discourse in middle school mathematics instruction. Journal of Advanced Academics, 19, 376-410.

Pino-Pasternak, D., Whitebread, D., \& Tolmie, A. (2010). A multidimensional analysis of parent-child interactions during academic tasks and their relationships with children's selfregulated learning. Cognition and Instruction, 28(3), 219-272.

Prediger, S., \& Pöhler, B. (2015). The interplay of micro- and macroscaffolding: An empirical reconstruction for the case of an intervention on percentages. ZDM Mathematics Education, 47(7). doi:10.1007/s11858-015-0723-2

Puntambekar, S., \& Hubscher, R. (2005). Tools for scaffolding students in a complex learning environment: What have we gained and what have we missed? Educational Psychologist, 40(1), 1-12.

Quintana, C., Reiser, B. J., Davis, E. A., Krajcik, J., Fretz, E., Duncan, R. G., \& Soloway, E. (2004). A scaffolding design framework for software to support science inquiry. Journal of the Learning Sciences, 13(3), 337-386.

Reiser, B. J., \& Tabak, I. (2014). Scaffolding. In R. K. Sawyer (Ed.), The Cambridge handbook of the learning sciences (pp. 44-62). Cambridge: Cambridge University Press.

Renshaw, P. (2013). The social cultural and emotional dimensions of scaffolding. Learning, Culture and Social Interaction, 2(1).

Rickard, A. (2014). Unpacking middle school students'; ideas about perimeter: A case study of mathematical discourse in the classroom. Mathematics Educator, 23(2), 60-87.

Roll, I., Holmes, N. G., Day, J., \& Bonn, D. (2012). Evaluating metacognitive scaffolding in guided invention activities. Instructional Science, 40(4), 691-710.

Rojas-Drummond, S., \& Mercer, N. (2003). Scaffolding the development of effective collaboration and learning. International Journal of Educational Research, 39(1), 99-111.

Scardamalia, M., \& Bereiter, C. (1994). Computer support for knowledge-building communities. Journal of the Learning Sciences, 3(3), 265-283.

Schukajlow, S., Kolter, J., \& Blum, W. (2015). Scaffolding mathematical modelling with a solution plan. ZDM Mathematics Education, 47(7). doi:10.1007/s11858-015-0707-2

Schukajlow, S., Leiss, D., Pekrun, R., Blum, W., Müller, M., \& Messner, R. (2012). Teaching methods for modelling problems and students' task-specific enjoyment, value, interest and self- efficacy expectations. Educational Studies in Mathematics, $79(2), 215-237$.

Searle, D. (1984). Scaffolding: Who's building whose building? Language Arts, 480-483.

Seethaler, P. M., Fuchs, L. S., Fuchs, D., \& Compton, D. L. (2012). Predicting first graders' development of calculation versus wordproblem performance: The role of dynamic assessment. Journal of Educational Psychology, 104(1), 224.

Shepard, L. A. (2005). Linking formative assessment to scaffolding. Educational Leadership, 63(3), 66-70.

Sherin, B. L., Reiser, B. J., \& Edelson, D. C. (2004). Scaffolding analysis: Extending the scaffolding metaphor to artifacts. The Journal of the Learning Sciences, 13(3), 387-421.

Sleep, L., \& Boerst, T. A. (2012). Preparing beginning teachers to elicit and interpret students' mathematical thinking. Teaching and Teacher Education, 28(7), 1038-1048.

Smit, J, (2013). Scaffolding language in multilingual mathematics classrooms (Dissertation). Utrecht: Utrecht University.

Smit, J., \& Van Eerde, H. A. A. (2011). A teacher's learning process in dual design research: Learning to scaffold language in a multilingual mathematics classroom. ZDM-The International Journal on Mathematics Education, 43(6-7), 889-900.

Smit, J., \& Van Eerde, H. A. A. (2013). What counts as evidence for the long-term conversation of whole-class scaffolding? Learning, Culture and Social Interaction, 2(1), 22-31.

Smit, J., Van Eerde, H. A. A., \& Bakker, A. (2013). A conversation of whole-class scaffolding. British Educational Research Journal, $39(5), 817-834$.

Solomon, Y. (2012). Finding a voice? Narrating the female self in mathematics. Educational Studies in Mathematics, 80(1-2), 171-183.

Speer, N. M., \& Wagner, J. F. (2009). Knowledge needed by a teacher to provide analytic scaffolding during undergraduate mathematics classroom discussions. Journal for Research in Mathematics Education, 530-562.

Stender, S. \& Kaiser, G. (2015). Scaffolding in complex modelling situations. ZDM Mathematics Education, 47(7). doi:10.1007/ s11858-015-0741-0

Stone, C. A. (1998a). The metaphor of scaffolding: Its utility for the field of learning disabilities. Journal of Learning Disabilities, 31(4), 344-364.

Stone, C. A. (1998b). Should we salvage the scaffolding metaphor? Journal of Learning Disabilities, 31(4), 409-413.

Tabak, I. (2004). Synergy: a complement to emerging patterns of distributed scaffolding. Journal of the Learning Sciences, 13(3), 305-335.

Tharp, R. G., \& Gallimore, R. (1991). Rousing minds to life: Teaching, learning, and schooling in social context. Cambridge University Press.

Toh, P. C., Leong, Y. H., Toh, T. L., Dindyal, J., Quek, K. S., Tay, E. G., \& Ho, F. H. (2014). The problem-solving approach in the teaching of number theory. International Journal of Mathematical Education in Science and Technology, 45(2), 241-255.

Tropper, N., Leiss, D., \& Hänze, M. (2015). Teachers' temporary support and worked-out examples as elements of scaffolding in mathematical modeling. ZDM Mathematics Education, 47(7). doi:10.1007/s11858-015-0718-z

Truxaw, M. P., \& DeFranco, T. C. (2007a). Lessons from Mr. Larson: An inductive model of teaching for orchestrating discourse. Mathematics Teacher, 101(4), 268-272.

Truxaw, M. P., \& DeFranco, T. C. (2007b). Mathematics in the making: Mapping verbal discourse in Polya's "let us teach guessing" lesson. Journal of Mathematical Behavior, 26(2), 96-114.

Truxaw, M. P., \& DeFranco, T. C. (2008). Mapping mathematics classroom discourse and its implications for models of teaching. Journal for Research in Mathematics Education, 39(5), 489-525. 
Truxaw, M. P., Gorgievski, N., \& DeFranco, T. C. (2008). Measuring $\mathrm{K} 8$ teachers' perceptions of discourse use in their mathematics classes. School Science and Mathematics, 108(2), 58.

Van de Pol, J., Volman, M., \& Beishuizen, J. (2010). Scaffolding in teacher-student interaction: A decade of research. Educational Psychology Review, 22(3), 271-296.

Visnovska, J., \& Cobb, P. (2015). Learning about whole-class scaffolding from a teacher professional development study. ZDM Mathematics Education, 47(7). doi:10.1007/s11858-015-0739-7

Vygotsky, L. S. (1978). Mind in society: The development of higher psychological processes. Cambridge: Harvard University Press.

Wagner, D., \& Herbel-Eisenmann, B. (2008). "Just don't": The suppression and invitation of dialogue in the mathematics classroom. Educational Studies in Mathematics, 67(2), 143-157.

Watson, A., \& De Geest, E. (2012). Learning coherent mathematics through sequences of microtasks: making a difference for secondary learners. International Journal of Science and Mathematics Education, 10(1), 213-235.

Wegerif, R. (2007). Dialogic, education and technology: Expanding the space of learning. New York: Routledge.

Wegerif, R. (2013). Dialogic: Education for the internet age. New York: Routledge.

Wells, G. (1999a). Dialogic inquiry: Toward a sociocultural practice and theory of education. Cambridge: Cambridge University Press.
Wells, G. (1999b). Dialogic inquiry: Towards a sociocultural practice and theory of education. Cambridge: Cambridge University Press.

Williams, S. R., \& Baxter, J. A. (1996). Dilemmas of discourseoriented teaching in one middle school mathematics classroom. The Elementary School Journal, 21-38.

Wood, D. (2003). The why? what? when? and how? of tutoring: The development of helping and tutoring skills in children. Literacy Teaching and Learning, 7(1\&2), 1-30.

Wood, D., Bruner, J. S., \& Ross, G. (1976). The role of tutoring in problem solving. Journal of Child Psychology and Psychiatry, 17, 89-100.

Wood, D., \& Middleton, D. (1975). A study of assisted problemsolving. British Journal of Psychology, 66(2), 181-191.

Zazkis, R., \& Koichu, B. (2015). A fictional dialogue on infinitude of primes: Introducing virtual duoethnography. Educational Studies in Mathematics, 88(2), 163-181.

Zolkower, B., Shreyar, S., \& Pérez, S. (2015). Teacher guidance of algebraic formula building: Functional grammatical analysis of a whole-class conversation. ZDM Mathematics Education, 47(7). doi:10.1007/s11858-015-0701-8 